Ayurlog: National Journal of Research in Ayurved Science

http://www.ayurlog.com Volume: $6^{\text {th }} \mid$ Issue: $5^{\text {th }} \mid$ August 2018

\title{
Management of Asthibhagna by Ayurvedic Concepts, a Review
}

Ghodke Shilpa Nandkumar*¹, Raut Subhash Yashwant $^{2}$

1. PG scholar,

2. Professor, Guide and Head of the Department,

Dept. of Shalyatantra, Government Ayurved College, Nagpur, Maharashtra

Corresponding author: Mob.: 9146072858; Email: shilpaghodke41@ gmail.com

\section{Abstract}

Ayurveda is a complete science of life where we get elaborate descriptions about prevention and management of disease. Sushruta has mentioned detailed diagnosis and management for all orthopedic injuries under the heading, Bhagna. Bhagna as described by Sushruta is not merely a condition of fracture but is the group of clinical entities musculoskeletal system with traumatic origin. The principle of Bhagna management defined by Sushruta centuries ago are as per the condition suggestive surgical or conservative treatment. Sushruta has described the fundamentals of fracture management like Reduction (Bhagnasthapna), Immobilization (Sthirikarna) and Rehabilitation (Sukhcheshta prasartwam). Also, he has described various types of Bandhanas, management of malunion, management of open fractures. Different types of management techniques have been described according to the types of fractures e.g. Talabhagna, Shirobhagna Chikitsa. Various modalities for the management of fracture developed down the centuries, but the basic fundamentals described by Sushruta are still appreciably relevant, rational and practical. This paper expounds the wisdom of orthopedic branch in ancient times especially fracture and it's management with possible modern correlations. It would be worthwhile to explore the concepts, theories and techniques which were practical thousand years ago hold true even in modern era.

Keywords: Asthibhagna, Ayurved, Management.

\section{Introduction:}

digenous system of medicine do not 1rmit themselves to just fulfilling the needs of primary health care, but also reach out to certain specialized areas. One such popular but little known area is that of fracture management. Today, we are able to examine fractured bone directly under radiological examination. In absence of this, Sushruta had evolved extremely useful, logical and detailed methods of determining the types of fractures and their management. The principles laid down by Ayurvedic texts are so relevant that they are practices even in the present times by the orthopedic surgeons.

In traditional Ayurveda practice, the fracture of bones and their treatment was mentioned in Sushruta samhita nidana sthana and chikitsa sthana from the view of surgical management in 1500 B.C. Many interesting facts have been described in ancient Ayurvedic classics on the management of fractures including 
different kinds of bandages and slings to be used.

This study helps to explore the hidden skills, powers and methods of identification and treatment of fractures according to ancient times and simultaneously comparing it to the treatment of fractures according to the highly accepted modern medicine.

\section{Aim and Objectives}

The aim of this study is to explore the concepts of management of fractures from the Ayurvedic point of view

- To identify the similarities and differences between the management of fractures according to conventional medicine and Ayurveda.

\section{Principles of Management}

\section{Management of Closed Fracture}

\section{Ayurvedic Perspective}

One should rise up the slipped down, press down the elevated one, retract the excessively thrown out and pull out that which has moved below. All joints, movable or immovable should be set to their normal position by these setting procedures traction, compression, extension and bandaging by a wise surgeon. ${ }^{1}$

\section{Bandaging techniques}

Bandaging should be done every week in soumya hritu, on every five days in moderate seasons and on every third day in hot seasons or as required by the condition of bhagna ${ }^{2}$.

\section{Modern perspective}

Simple fractures are managed by conservative and operative methods. Management of fractures by closed reduction consists of

- Resuscitation

- Reduction

- Retention

- Rehabilitation

Resuscitation is the topmost priority if the patient is in shock following a fracture

Reduction of the fracture fragments if it is displaced. Usually it is done under general anesthesia after adequate radiological study. There are two methods of reduction viz. Closed reduction and open reduction.

Methods of open reduction

- Exposure

- Reduction

- Temporary stabilization

- Definitive stabilization

etention: once the fracture fragments are educed, it has to be retained in that position till the fracture unites. Retention methods may be by plaster of Paris, by continuous traction, use of functional braces.

Rehabilitation is by way of physiotherapy and exercises.

\section{Management of Compound Fractures}

\section{Ayurvedic Perspective}

In case of compound fracture, the wound should be treated with paste of plants mixed with plenty of ghrita and honey. The remaining regimen should be as in fractures. Medicated fats described in the treatment of vatvyadhi may also be used here.

\section{Modern Perspective}

It follows a protocol like

- General physical examination 
- Systemic examination

- Examination of compound injury

- Investigations like $\mathrm{Hb}, \mathrm{BT}, \mathrm{CT}, \mathrm{X}$ ray.

The aim of treatment is

- To convert a contaminated wound into a clean wound

- To establish union in a good position

- To prevent pyogenic and clostridial infections.

The treatment plan includes

1. Debridement It consists of following steps

- Exploration

- Excision

- Evacuation

- External fixators.

2. Definitive wound care

\section{Complications and Detrimental Factors}

\section{Ayurvedic Perspective}

Out of the fractures, churnita, chinna, atipatita, and majjanugata are curable with difficulty. The bone which has been crushed into very small pieces, that which causes sound on touching, in which pieces of bone have entered into the marrow cavity, the condition where, by trauma very little portion is left inside the body, that condition in which raising the fracture portion makes it sink into the marrow - all these kinds are difficult to cure.

\section{Modern Perspective}

Acute complications

- Shock

- ARDS

- Neuro vascular injuries

- Compartmental syndrome

- Crush syndrome

- Infection

- Gas gangrene

- Tetanus
- Hypovolemic shock

Chronic complications

- Delayed union

- Malunion

- Non union

- Shortening of long bones

- Avascular necrosis

- Joint stiffness

- Post traumatic arthritis

Unique Features of Ayurvedic Treatment of Fracture Healing

\section{* Special Decoction}

Well cooled Decoction of Nyagrodhadi Drugs should be used for sprinkling while in case of painful condition, laghupanchamula siddha dugdha should be used for sprinkling, lukewarm cakrataila can also be used.

After removing the bandage, the area should be bathed with decoction of drugs of Nyagrodhadi gana

\section{Special Dietary and herbal Supplements}

The patient should be provided with weight promoting food and drinks ${ }^{4}$.

The patient of fracture should drink grishtikshira added with ghee and boiled with madhur drugs 5 .

\section{Conclusion}

Many similarities can be found in both Ayurveda and modern medicine in the understanding and treatment of fractures as both fields hold excessive force and pressure on the bone. It can be concluded that the principles laid down by Ayurvedic texts are extremely relevant and many of them are practiced by the modern orthopedic surgeons even in the present time. It would also probably be 
worthwhile, in the time to come, to explore the role of diet and the decoction mentioned in the Ayurveda for accentuating fracture healing.

\section{References:}

1. Acharya Yadavji Trikamji, Acharya Narayana Ram., Sushruta, Susrutsamhita,Varanasi, Chaukhamba Surbharti Prakashat; 2014;
Chikitsasthana, Bhagnachikitsa adhyay, p- 416

2. Ibid Acharya Yadavji Trikamji, Acharya Narayana Ram., Sushruta, Susrutsamhita, p- 415

3. Ibid Acharya Yadavji Trikamji, Acharya Narayana Ram., Sushruta, Susrutsamhita,, p- 415

4. Ibid Acharya Yadavji Trikamji, Acharya Narayana Ram., Sushruta, Susrutsamhita,, p- 415

5. Ibid Acharya Yadavji Trikamji, Acharya Narayana Ram., Sushruta, Susrutsamhita,, p- 415

\section{Cite article}

Management of Asthibhagna by Ayurvedic Concepts, a Review Ghodke Shilpa Nandkumar, Raut Subhash Yashwant 